\title{
A Simple and Accurate Gas Buret
}

\author{
J. A. Lely \\ Twente University of Technology, Department of Chemical Technology, Enschede, The Netherlands
}

Usually it is a cumbersome affair to work with an ordinary gas buret. Generally a buret with a stopcock on top and a liquid sealing at the bottom is used. Before each reading the liquid inside the buret has to be leveled with the liquid outside. Experimental conditions often require a mercury seal. The disadvantages are inaccurate readings and varying pressure during rapid volume changes.

Now we will describe an alternative device which is easy to make. It is based on an invention of Porter ${ }^{1}$ who constructed a floating piston, sealed with a mercury O-ring. This piston is applied commercially in the Vol-U-Meter ${ }^{\circledR}$ Flow Rate Calibrator of Brooks Instruments. ${ }^{2}$

Almost any ordinary analytical buret (10-, 50-, or 100-ml) serves the purpose. The piston floats practically frictionless on the gas and remains perfectly tight over long periods. The pressure in the buret is constant at any time and is only slightly higher than ambient pressure (5-15 Torr). The only requirement for the buret is that it should have a good circular and constant bore over its calibrated length. A tolerance of about $0.1 \mathrm{~mm}$ is permissible. Most commercial burets fulfill this requirement.

The piston itself can be manufactured easily from (low friction) PTFE, PVC, or other suitable plastic materials. A dimensional sketch is given below.

The matching of buret and piston is carried out as follows. With a given buret in upright position (stopcock closed) the piston without mercury should sink down smoothly and slowly. If it sticks somewhere in the buret, its diameter should be diminished by about $0.03 \mathrm{~mm}$. Repeat if necessary.

After filling the piston with mercury through the central hole the filling height in the center should be $10-15 \mathrm{~mm}$ in order to overcome the back pressure of the mercury caused by its surface tension and high contact angle. In this way, the mercury O-ring can stand a pressure difference (by the weight of the piston) of 60 Torr or more at a slit width of $0.1 \mathrm{~mm}$ between piston and tube. Measurements at different pressures can be carried out by applying the desired gas pressure on top of the piston. An extra advantage of this type of buret is that the mercury $\mathrm{O}$-ring facilitates readings and enhances accuracy because of the absence of parallax.

Some examples may illustrate the use of this buret in (student!) experiments.

(1) Measurements of adsorption isotherms in student experiments as described by Daniels. ${ }^{3}$ Accuracy, reproducibility, and ease of handling are much better than with the customary gas buret.

(2) Evolution of $\mathrm{N}_{2}$ by decomposition of benzene diazoniumchloride solution. The exponential curve of first-order kinetics is found with well-stirred solutions.

(3) Solubility and absorption rate of gases in liquids (e.g. $\mathrm{CH}_{4}$ or $\mathrm{CO}_{2}$ in $\mathrm{CH}_{3} \mathrm{OH}$ ). Here also with well-stirred liquids first-order kinetics are found, and with the Guggenheim relation ${ }^{4}$ solubility may be calculated before the end point is reached.
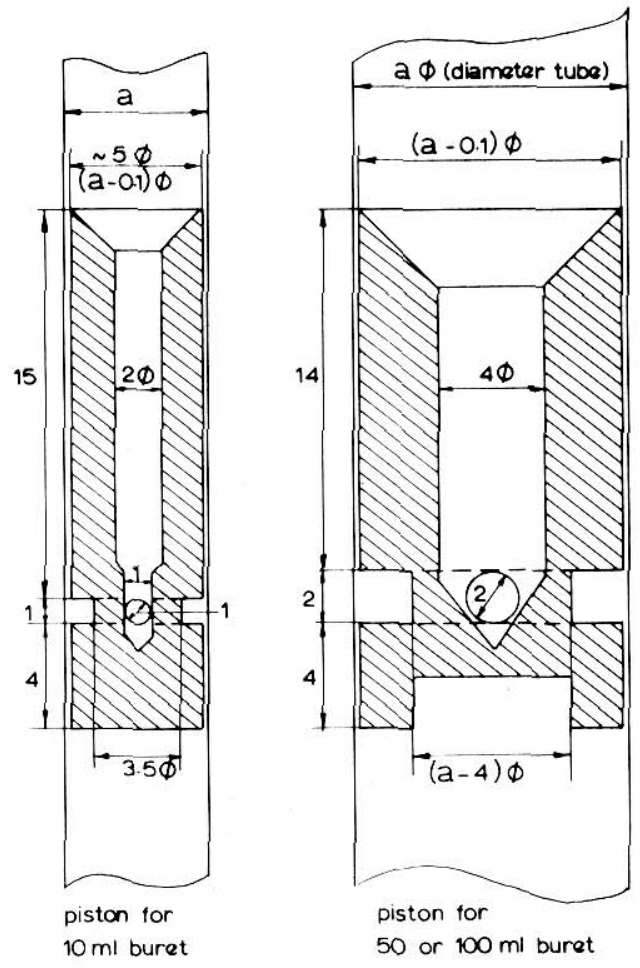

Dimensional sketch of piston. Dimensions in $\mathrm{mm}$

(4) The density of a substance may be determined by measuring the gas volume of a previously evacuated (small) vessel with and without sample. With a sample of $0.1 \mathrm{~cm}^{3}$ the accuracy is $\pm 2 \%$. This method is especially useful when the substance reacts with or is soluble in all common liquids, is non-wettable or porous. By using suitable gases (He) adsorption can be avoided.

(5) Of course these burets may also be used for the calibration of small flow meters or as a gasometer for which purposes the Vol-U-Meter ${ }^{\circledR}$ of Brooks Instruments ${ }^{2}$ is developed. These instruments cannot be used for the other applications on account of their large scale increments.

${ }^{1}$ Porter, G. K., U.S. Patent 2,927,829, March 8, 1960. Not cited in Chemical Abstracts.

2 Brooks Instrument Division, Emerson Electric Co., Hatfield, PA 19440.

${ }^{3}$ Daniels, F., Williams, J. W., Bender, P., Alberty, R. A., and Cornwell, C. D., "Experimental Physical Chemistry," 6th Ed., McGraw-Hill Book Co., 1962, 333-338.

${ }^{4}$ Guggenheim, Phil. Mag., 2, (1926) 538. 